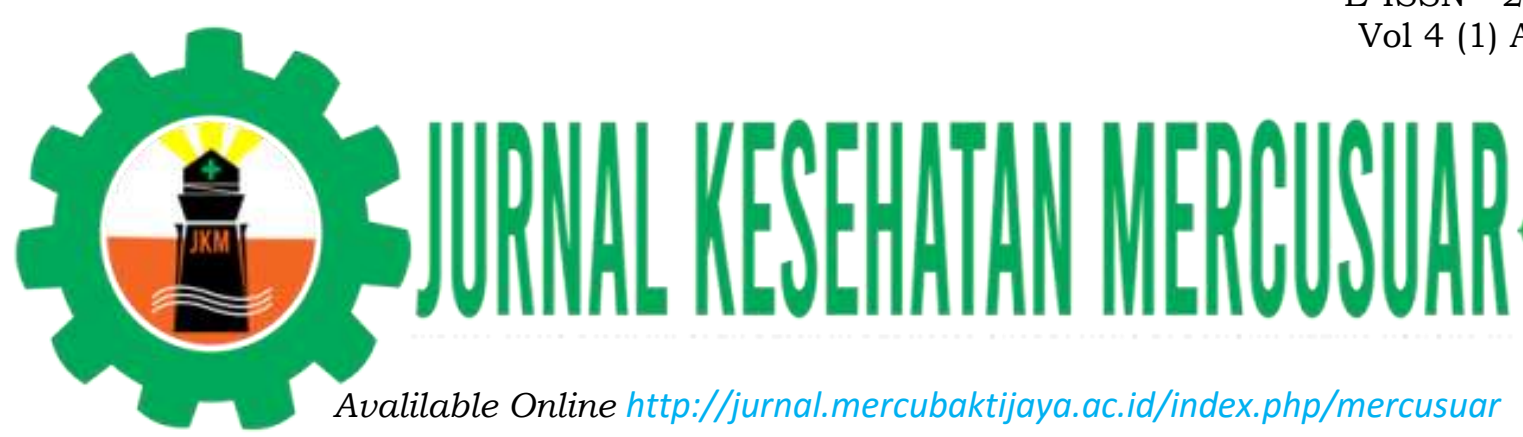

(1) April 2021

\title{
PERAN BIDAN Dalam PELAYANAN ANTENATAL Pada MASA PANDEMI COVID 19
}

\author{
Farida Ariyani $^{1^{*}}$, Widya Lestari ${ }^{2}$, Nila Eza Fitria ${ }^{3}$, Eka Putri Primasari ${ }^{4}$ \\ ${ }^{1 * 2,3,4}$ Program Studi D III Kebidanan STIKes MERCUBAKTIJAYA Padang \\ "Email Penulis Korespondensi: dzakwan.sayang@gmail.com
}

\begin{abstract}
Currently, Indonesia and the world are facing the Covid Pandemic 19. Pregnancy services are one of the services affected both in terms of access and quality. As health workers who are at the forefront of neonatal maternal services throughout Indonesia, midwives must be able to manage, utilize their resources effectively and efficiently in breaking the chain of transmission, both at the individual, family and community levels. This study aims to describe the role of midwives in antenatal care during the Covid-19 pandemic. The method used in this research is descriptive which describes the knowledge and role of midwives in the First Level Health Service Facilities (FKTP) in West Sumatra. The sample of this research is 55 midwives who provide antenatal services in FKTP. Data were collected using an online questionnaire that was sent through an electronic questionnaire format. Furthermore, the data were analyzed univariately. The results showed that $52.7 \%$ of respondents had high knowledge about services for pregnant women during the Covid 19 pandemic, $98.2 \%$ of respondents played a good role in the services for pregnant women during the Covid 19 pandemic. It is hoped that the first level health service agencies will complete the personal protective equipment needed in ANC services and provide reward to midwives who provide ANC services.
\end{abstract}

Keywords: Antenatal care during the Covid-19 pandemic; Knowledge; The role of midwives

\begin{abstract}
ABSTRAK
Saat ini Indonesia dan Dunia sedang menghadapi Pandemic Covid 19. Pelayanan kehamilan menjadi salah satu layanan yang terkena dampak baik secara akses maupun kualitas. Sebagai tenaga kesehatan yang berada pada garis depan dalam pelayanan maternal neonatal di seluruh Indonesia, bidan harus mampu mengelola, memanfaatkan sumber daya yang dimilikinya secara efektif dan efisien dalam memutus mata rantai penularan, baik di level individu, keluarga dan masyarakat. Penelitian ini bertujuan menggambarkan peran bidan dalam pelayanan antenatal pada masa pandemic covid-19. Metoda yang dipergunakan dalam penelitian ini adalah deskriptif yang menggambarkan pengetahuan dan peran bidan di Fasilitas Pelayanan Kesehatan Tingkat Pertama (FKTP) Di Sumatera Barat. Sampel penelitian adalah bidan yang memberikan pelayanan antenatal di FKTP sebanyak 55 orang. Data dikumpulkan dengan menggunakan kuesioner online yang dikirimkan melalui format kuesioner elektronik. Selanjutnya data dianalisa secara univariat. Hasil penelitian didapatkan sebanyak 52,7\% responden memiliki pengetahuan yang tinggi tentang pelayanan ibu hamil masa pandemic Covid 19, 98,2\% responden berperan baik dalam pelayanan ibu hamil masa pandemic Covid 19. Diharapkan instansi pelayanan kesehatan tingkat pertama, melengkapi APD yang dibutuhkan dalam layanan ANC dan memberikan penghargaan kepada bidan yang memberikan layanan ANC.
\end{abstract}

Kata kunci : Pelayanan antenatal masa pandemic covid-19; peran bidan 


\section{PENDAHULUAN}

Berdasarkan data Provinsi Sumatera Barat per 14 Mei 2020 terdapat 371 kasus positif Covid 19, 8.844 orang ODP (Orang Dalam Pemantauan), dan 645 orang PDP (Pasien Dalam Pengawasan)(IT Diskominfo, 2020). Bidan yang berada di Fasilitas Kesehatan Tingkat Primer (FKTP) seperti Puskesmas, Praktek Mandiri Bidan/ Pustu/ Polindes, memiliki peran yang sangat penting dalam melakukan prevensi, deteksi dan respon awal dalam pencegahan dan pengendalian Covid 19. Sebagai tenaga kesehatan yang berada pada garis depan dalam pelayanan maternal neonatal di seluruh Indonesia, bidan harus mampu mengelola, memanfaatkan sumber daya yang dimilikinya secara efektif dan efisien dalam memutus mata rantai penularan, baik di level individu, keluarga dan masyarakat.

Berdasarkan data jumlah sarana kesehatan tingkat dasar di Profinsi Sumatera Barat tahun 2017, jumlah FKTP yang berada di lingkungan Dinas Kesehatan Profinsi Sumatera Barat sebanyak 1.203 faskes dengan rincian Puskesmas sebanyak 272 dan PMB/Pustu/Polindes sebanyak 931 (Dinkes Sumatera Barat, 2017). Data IBI Profinsi Sumbar menerangkan bahwa jumlah BPM di Profinsi Sumatera Barat berjumlah 1.083 (IBI, 2020)

Wanita hamil mengalami perubahan imunologis dan fisiologis yang mungkin membuatnya lebih rentan terhadap infeksi pernapasan virus, termasuk COVID19.Wanita hamil juga berisiko terhadap penyakit parah, morbiditas, atau mortalitas dibandingkan dengan populasi umum.Wanita hamil juga rentan terhadap Covid 19, meskipun sampai saat ini belum ada laporan ilmiah atau bukti yang diterbitkan(Tim Kerja Kementerian Dalam Negeri, 2020)

Sehubungan dengan hal diatas dalam pemberian pelayanan kebidanan, Kementerian Kesehatan Indonesia telah mengeluarkan pedoman bagi ibu hamil, ibu nifas dan bayi baru lahir selama Social Distancing. Pedoman ini bertujuan untuk memberikan arahan ke pada tenaga kesehatan dalam memberikan pelayanan kepada ibu hamil, ibu nifas dan bayi baru lahir dengan menekankan kepada prinsip pencegahan dan manajemen covid 19 di fasilitas kesehatan(Gugus Tugas Percepatan Penurunan Covid-19, 2020). Selain dari pedoman diatas, IBI sebagai organisasi profesi yang mengayomi bidan dalam memberikan pelayanan kebidanan, juga turut memberikan beberapa upaya untuk mendukung pelayanan maternal neonatal di era pandemi covid 19. IBI juga mengeluarkan panduan praktis pelayanan kebidanan pada Praktik Mandiri Bidan (PMB) selama situasi Pandemi covid 19 khususnya pada pelayanan ibu hamil, ibu bersalin, ibu nifas dan bayi baru lahir dan pelayanan Keluarga Berencana (KB)(Emi, 2020).

Sehubungan dengan data diatas maka penulis tertarik untuk melihat bagaimana peran bidan dalam pelayanan ibu hamil (Antenatal Care) yang dilakukan oleh bidan di FKTP di Sumatera Barat selama masa pandemi Covid 19 di di Fasilitas Kesehatan Tingkat Primer Provinsi Sumatera Barat tahun 2020.

\section{METODE PENELITIAN}

Penelitian ini adalah penelitian deskriptif. Penelitian ini akan menggambarkan karakteristik bidan,pengetahuan dan peran bidan dalam pelayanan ibu hamil (Ante Natal Care) pada masa pandemi Covid 19 di Fasilitas Kesehatan Tingkat Primer Profinsi Sumatera Barat tahun 2020 yang meliputi upaya pencegahan dan manajemen pelayanan di FKTP.

Sampel atau responden dalam penelitian ini ialah bidan-bidan yang terlibat memberikan pelayanan ANC di Fasilitas Kesehatan Tingkat Primer Profinsi Sumatera Barat tahun 2020 yang berjumlah 55 orang. Pengumpulan data 
dilakukan secara online yaitu dengan cara menyebar link kuisioner kepada bidan melalui media sosial (WhatsApp, email, facebook, dan telegram).Prosedur penelitian ini terdiri dari proses administrasi dan prosedur teknis. Prosedur administrasi terdiri dari mengurus surat-suratterkait pelaksanaan penelitian. Pengolahan data dilakukan melalui proses editing, coding, entry, dan cleaning. Data dianalisa secara univariat untuk mengetahui gambaran atau distribusi frekuensi. Data dianalisa dengan menggunakan software Statistics SPSS. Hasil analisis univariat akan ditampilkan berupa tabel distribusi frekuensi.

\section{HASIL DAN PEMBAHASAN}

Penelitian yang telah dilakukan terhadap 55 orang bidan yang memberikan pelayanan antenatal, didapatkan hasil sebagai berikut:

Tabel 1.Karakteristik Responden

\begin{tabular}{ccc}
\hline Karakteristik & $\mathbf{n}$ & $\mathbf{\%}$ \\
\hline Usia & 101 & 20.20 \\
$-\quad \geq 33$ tahun & 149 & 29.80 \\
$-\quad<33$ tahun & 250 & 50.00 \\
\hline Masa Kerja & 500 & 100.00 \\
$-\quad \geq 10$ tahun & & \\
$-\quad<10$ tahun & & \\
\hline
\end{tabular}

Pada tabel 1 dapat diketahui bahwa dari 55 responden sebanyak 29 orang $(52,8 \%)$ memiliki usia < 33 tahun dan dari 55 orang responden, sebanyak 28 orang $(51 \%)$ berusia $<10$ tahun

\section{Tabel 2 Distribusi frekuensi Pengetahuan Bidan tentang Pelayanan Ibu Hamil pada Masa Pandemi Covid 19}

\begin{tabular}{ccc}
\hline Kategori & n & \% \\
\hline Tinggi & 29 & 52,7 \\
Rendah & 26 & 47,3 \\
\hline Jumlah & 55 & 100 \\
\hline
\end{tabular}

Berdasarkan tabel diatas diperoleh bahwa dari 55 orang responden, sebanyak 54 orang $(52,7 \%)$ memiliki pengetahuan yang tinggi tentang pelayanan ibu hamil pada masa pandemic Covid 19

Berdasarkan tabel 2 diatas, menunjukkan bahwa separuh responden memiliki pengetahuan yang tinggi tentang pelayanan ibu hamil pada masa pandemic Covid 19.

Dari 29 responden yang memiliki pengetahuan tinggi, 59\% mengetahui tentang bagaimana pelayanan ANC di FKTP pada masa pandemic, 90\% mengetahui pemberi pelayanan ANC di FKTP, 93\% mengetahui proses skrining ibu hamil di FKTP, 62\% mengetahui tentang jenis APD yang dipergunakan dalam pemberian pelayanan ANC masa pandemic, 90\% mengetahui edukasi yang perlu disampaikan kepada ibu hamil untuk mencegah penularan Covid 19, 90\% mengetahui pemantau tanda bahaya ibu hamil pada masa pandemic, 66\% mengetahui tentang cara melakukan pemeriksaan fisik pada ibu hamil masa pandemic, 93\% mengetahui tentang jenis layanan ANC pada masa pandemic, dan $76 \%$ mengetahui tentang penanganan awal pada ibu hamil yang memiliki riwayat perjalanan ke daerah terjangkit Covid 19.

Jika dilihat dari sisi karakteristiknya, responden yang memiliki pengetahuan tinggi sebanyak $66 \%$ berusia $\geq 33$ tahun dan $62 \%$ memiliki masa kerja $\geq 10$ tahun, sehingga dapat diasumsikan bahwa responden tersebut telah memiliki banyak pengalaman dalam pelayanan ante natal care. Hasil penelitian ini sama halnya dengan temuan penelitian Abu, Kusumawati, Werdani (2015) bahwa variabel yang memiliki korelasi dengan pelayanan ANC adalah umur $(\mathrm{r}=0,445, \mathrm{p}$ value $=0,014)$, masa kerja $(\mathrm{r}=0,401, \mathrm{p}$ value 0,028$)$. 
Dengan bertambahnya umur seseorang, maka terjadi perubahan pada fisik dan psikologi sehingga akan semakin mudah menerima dan mencari informasi yang dibutuhkan. Hal ini sesuai dengan pendapat Andriani S (2009) dalam Abu, Kusumawati, Werdani (2015) yang menyatakan bahwa umur merupakan ciri dari kedewasaan fisik dan kematangan kepribadian yang erat hubungannya dengan keingintahuan, pengambilan keputusan dan kemampuan menyelesaikan masalah serta stabil/ tenang secara emosional(Abu, Kusumawati, \& Werdani, 2017).

Selain dari pengaruh umur dan masa kerja bidan, kontribusi Organisasi Profesi Bidan (IBI), profesi kesehatan lainnya dan pemerintah turut menyumbang peningkatan pengetahuan bidan tentang pelayanan ANC masa pandemic. Upaya yang dilakukan oleh pemerintah dan organisasi profesi berupa diterbitkannya Protokol dan Pedoman Pelayanan khususnya pelayanan ibu dan anak pada masa pandemic, kegiatan sosialisasi prosedurpelayanan masa pandemi, memfasilitasi peningkatan pengetahuan dan kapasitas anggota melalui webinar/ modul online, bantuan APD untuk tenaga kesehatan, komunikasi dan koordinasi PD dengan PC secara virtual, advokasi IBI kepada stakeholder untuk memperoleh dukungan danbantuan bagi anggota IBI, dan banyak kegiatan lainnya. $\mathrm{Hal}$ ini mengindikasikan tingginya perhatian pemerintah dan organisasi terhadap kebutuhan dan keberlanjutan pelayanan kebidanan di masa pandemic Covid 19 (Jubaedah, 2020).

\section{Tabel 3 Distribusi frekuensi Peran Bidan dalam Pelayanan Ibu Hamil (Ante Natal Care)pada Masa Pandemi Covid 19}

\begin{tabular}{ccc}
\hline Kategori & n & \% \\
\hline Baik & 54 & 98.2 \\
Cukup & 1 & 1,8 \\
Kurang & 0 & 0 \\
\hline Jumlah & 55 & 100 \\
\hline
\end{tabular}

Berdasarkan tabel diatas diperoleh bahwa dari 55 orang responden sebanyak 54 orang $(98,2 \%)$ berperan baik dalam pelayanan ibu hamil (Ante Natal Care) pada masa pandemic Covid 19.

Responden yang memiliki peran yang baik dalam pelayanan ibu hamil (ANC) masa pandemic melakukan upaya sebagai berikut mengunakan APD sesuai dengan pedoman pelayanan pasien masa pandemic, melayani pasien sesuai prosedur tetap (protap), memberikan konseling pada setiap kunjungan, responden telah mendapatkan sosialisasi tentang pelayanan ANC masa pandemic sebelum memberikan pelayanan kepada ibu hamil, memfasilitasi pelayanan ibu hamil melalui media social, menerima kontrak/ janji jadwal pelayanan ibu hamil melalui media social, menerapkan hand higiene dan physical distancing, melakukan desinfensi secara rutin pada benda di FKTP yang disentuh oleh pasien dan menetapkan jumlah kunjungan harian pelayanan ibu hamil.

Hal yang sama juga ditemukan Ersila, Setyaningsih, Putri A (2015) dalam penelitianya tentang motivasi bidan dalam pelaksanaan Antenatal Care terpadu bahwa 51,2\% responden (bidan) memiliki motivasi yang tinggi dalam pelaksanaan ANC terpadu di Puskesmas Pekalongan (Ersila, Setyaningsih, \& A, 2015).

Berdasarkan jawaban responden diatas dapat diasumsikan bahwa responden memiliki kepatuhan dan motivasi yang tinggi dalam memberikan pelayanan ANC masa pandemic. Hal ini dapat disebabkan karena responden memiliki dorongan dari dalam diri sendiri akan pentingnya pelayanan ANC pada ibu hamil pada masa pandemic atau dorongan tersebut didapatkan lingkungan kerja seperti dari rekan kerja atau atasan.

Asumsi ini diperkuat oleh pendapat Dalyono (2005) dalam Ersila, Setyaningsih, Putri A (2015) yang menyatakan bahwa motivasi yang berasal 
dari dalam (intrinsic) seperti dorongan yang datang dari hati sanubari, umumnya karena kesadaran akan pentingnya sesuatu dan motivasi yang berasal dari luar (ekstrinsik) seperti dorongan yang datang dari lingkungan, misal orang tua, teman, anggota dan masyarakat(Ersila et al., 2015).

Motivasi atau dorongan yang tinggi dalam pemberian pelayanan ANC meskipun adanya pembatasan layanan tidak menjadi hambatan dalam memberikan pelayanan ANC. Hal ini dibuktikan dari jawaban responden bahwa sebagian besar setuju memberikan pelayanan/ edukasi dengan menggunakan media social.Penggunaan KIE elektronik melalui media social saat ini dianggap paling efektif dan efisien untuk meningkatkan pengetahuan dan perilaku ibu hamil dalam upaya menjaga dan meningkat kesehatan ibu hamil di masa pandemic. Hal ini senada dengan hasil pengabdian masyarakat yang dilakukan Anggraini, Karyus, Kanis, Sari, Imantika (2020) bahwa terjadi peningkatan pengetahuan yang baik pada ibu hamil setelah diadakan e-KIE dengan peningkatan pengetahuan dari 1,4\% menjadi 93\%; dan peningkatan perilaku dari 14,1\% menjadi 97,2\%(Angraini, Karyus, Kania, Sari, \& Imantika, 2020).

Selain dari pelayanan ANC yang dilakukan dengan bantuan media social, ketersediaan alat pelindung diri di FKTP turut memberikan kontribusi yang tinggi sehingga bidan tidak merasa cemas dan takut dalam memberikan pelayanan. Setiap tenaga kesehatan tentunya memiliki ketakutan/ kecemasan akan tertularnya Covid 19, namun dengan tersedianya APD ini dan dukungan dari rekan serta atasan, hal ini membuat bidan mampu memberikan pelayanan ANC yang baik.

Hal ini diperkuat oleh hasil penelitian Wari, Adiesti, Yuliani (2020) tentang kecemasan bidan dalam memberikan pelayanan kebidanan di masa Pandemi
Covid 19 bahwa sebanyak $63,8 \%$ bidan pernah kontak dengan pasien Covid 19, $8,6 \%$ sedang merawat pasien Covid 19, $55,2 \%$ bidan tidak cemas dalam memberikan pelayanan kebidanan masa pandemic, $60,3 \%$ APD tersedia cukup(Wari, Adiesti, \& Yuliani, 2020).

\section{SIMPULAN}

Dari 55 responden, separuhnya memiliki pengetahuan yang tinggi tentang pelayanan ibu hamil pada masa pandemic Covid 19 dan sebagian besar responden berperan baik dalam pelayanan ibu hamil (Ante Natal Care) pada masa pandemic Covid 19. Diharapkan kepada instansi pelayanan memberikan sosialisasi secara menyeluruh kepada bidan pemberi pelayanan ANC tentang pedoman atau protocol pelayanan ANC masa pandemic Covid 19 dan melakukan supervise terhadap pelaksanaan protocol pelayanan ANC pada ibu hamil masa Pandemi Covid 19.

\section{UCAPAN TERIMAKASIH}

Ucapan terimakasih kami sampaikan kepada 1) Yayasan dan STIKes MERCUBAKTIJAYA Padang yang telah memberikan bantuan dana dan dukungan serta 2) Responden yang telah berpartisipasi dalam penelitian ini.

\section{DAFTAR PUSTAKA}

Abu, A. D. K. H., Kusumawati, Y., \& Werdani, K. E. (2017). Hubungan Karakteristik Bidan Dengan Mutu Pelayanan Antenatal Care Berdasarkan Standar Operasional. Jurnal Kesehatan Masyarakat Andalas, $\quad$ 10(1), 94. https://doi.org/10.24893/jkma.v10i1. 169

Angraini, D. I., Karyus, A., Kania, S., Sari, M. I., \& Imantika, E. (2020). Penerapan eKIE ( Komunikasi , Informasi, dan Edukasi Elektronik) Dalam Upaya Meningkatkan Kesehatan Ibu Hamil Di Era New Normal. 66-69. 
Dinkes Sumatera Barat. (2017). Profil Kesehatan Provinsi Sumatera Barat.

Emi, N. (2020). Peran IBI dlm pelayanan maternal diera pandemi covid-19.

Ersila, W., Setyaningsih, P., \& A, A. (2015). Motivasi Bidan Dalam Pelaksanaan Antenatal Care Terpadu. Jurnal Ilmiah Kesehatan, 8(2), 96802.

Gugus Tugas Percepatan Penurunan Covid-19. Protokol Petunjuk Praktis Layanan Kesehatan Ibu dan Bayi Baru Lahir Selama Pandemi COVID-19. , 4 Protokol Gugus Tugas Percepatan Penanganan Covid-19 Ri § (2020).

IT Diskominfo. (2020). Data Pantauan COVID-19 Provinsi Sumatera Barat Informasi Publikasi Provinsi
Sumatera Barat.

Jubaedah, A. (2020). Situasi pelayanan kebidanan di indonesia dalam masa pandemi covid - 19.

Tim Kerja Kementerian Dalam Negeri. (2020). Pedoman Umum Menghadapi Pandemi Covid-19 Bagi Pemerintah Daerah: Pencegahan, Pengendalian, Diagnosis dan Manajemen. https://doi.org/10.1017/CBO9781107 415324.004

Wari, F. E., Adiesti, F., \& Yuliani, F. (2020). Kecemasan Bidan Dalam Memberikan Pelayanan Kebidanan Pada Masa Pandemi Covid-19. Journal of Chemical Information and Modeling, 12(9), 1689-1699. 